\title{
The Rate of Growth of Salmonella typhimurium with Proline or Glutamate as Sole C Source
}

\author{
By O. MAALØE AND M. H. RICHMOND* \\ University Institute of Microbiology, Copenhagen, Denmark
}

(Received 12 June 1961)

\begin{abstract}
SUMMARY
Salmonella typhimurium will grow in simple defined media containing proline or glutamate as sole carbon source; in these media the organisms grew at 0.7 and 0.9 doublings/hr., respectively. Since most of the proline fed to the organisms is converted endogenously to cell material via glutamate, an attempt was made to see what reaction limited growth when the organisms were growing in proline as sole carbon source. The results suggest that the step which controls the conversion of proline to glutamate endogenously is the rate-limiting step. The uptake of proline from the medium to the free amino-acid pool did not appear to be rate limiting under these conditions. There was no evidence that the need to synthesize additional enzyme proteins (the proline degradative pathway) was responsible for the decreased growth rate of organisms growing on proline alone.
\end{abstract}

\section{INTRODUCTION}

The growth rate of bacteria is known to vary widely depending on the composition of the growth medium. Thus, by the use of appropriate media balanced growth of Salmonella typhimurium has been studied at rates anywhere from 0.6 to 2.8 doublings/ hr. (Schaechter, Maaløe \& Kjeldgaard, 1958). No attempt was made to determine which metabolic reactions were responsible for the observed differences in growth rate. We have now tried to identify such reactions by comparing the growth of S. typhimurium in simple defined media containing L-glutamic acid or L-proline as sole carbon source. These compounds were chosen since the only known pathway whereby proline is degraded endogenously to supply carbon for cell growth involves conversion to glutamic acid. As the growth rate on glutamic acid is higher than that on proline, there seemed to be some chance of locating the rate-limiting reaction in the proline culture. Preliminary experiments with $S$. typhimurium showed that, as expected, most of the carbon from proline flowed to the cell by way of endogenous glutamic acid. The slower growth on proline could therefore be due to one or more of the following causes: (1) the rate of flow of proline into organisms might limit the supply of carbon; (2) the rate of conversion of proline to glutamic acid within the cell could be limiting; (3) the induced enzymes which convert proline to glutamic acid might constitute such a large proportion of the total cell protein that other

* Present address: Bacterial Physiology Division, National Institute for Medical Research, The Ridgeway, Mill Hill, London, N.W. 7. 
essential enzyme systems would be relatively reduced. The only well-authenticated case for the production of an enzyme decreasing the growth rate of an organism was provided by Novick \& Weiner (1957) who showed that 'gratuitous' induction of $\beta$-galactosidase in Escherichia coli significantly increased the doubling time of cultures growing in a chemostat. The experiments described below favour the conclusion that conversion of proline to glutamic acid is the rate-limiting reaction in organisms growing in a simple defined medium with L-proline as the sole carbon source.

\section{METHODS}

Organisms and growth media. Salmonella typhimurium (the strain used by Schaechter et al. 1958) was maintained routinely by subculture every 2 or 3 weeks on minimal medium agar containing $2 \mathrm{mg}$. L-proline $/ \mathrm{ml}$. The slopes were incubated for $48 \mathrm{hr}$. at $37^{\circ}$ and then stored at $2^{\circ}$ until required for use. The purity and identity of the cultures were checked at intervals by plating out and by slide agglutination with specific sera prepared against the parent strain. Experiments in liquid media were carried out in medium 63 to which different concentrations of L-proline or L-glutamic acid were added before use. The medium 63 contains: $\mathrm{KH}_{2} \mathrm{PO}_{4}, 0 \cdot \mathbf{1} \mathbf{M}$; $\mathrm{NH}_{4} \mathrm{Cl}, 0.02 \mathrm{M} ; \mathrm{MgSO}_{4}, 10^{-3} \mathrm{M} ; \mathrm{FeCl}_{3}, 10^{-5} \mathrm{M} ; \mathrm{KOH}$ to $\mathrm{pH} \mathrm{7 \cdot 0 \pm 0 \cdot 1.}$

Amino acids. L-proline and L-glutamic acid (California Corporation for Biochemical Research, Grade A) were used throughout. The L-glutamic acid solutions were pre-adjusted to $\mathrm{pH} 7 \cdot 0$ with $0 \cdot 1 \mathrm{~N}-\mathrm{NaOH}$. The L- (generally labelled) $-\left({ }^{14} \mathrm{C}\right.$ )-proline was obtained from the Radiochemical Centre, Amersham, Buckinghamshire, England. It was found to contain about 5-6\% of radiochemical impurity and was purified by two-dimensional chromatography in $n$-butanol+acetic acid + water followed by phenol + ammonia (see later).

Membrane filters. Filters with pore diameter about $400 \mathrm{~m} \mu$ were obtained from the Membranfilter-Gesellschaft, Göttingen, Germany. These filters were found to contain large amounts of glycerol added as a plasticizer during manufacture. Consequently cultures constituted with filtered organisms always contained glycerol. Control experiments were carried out with filters from which glycerol had been removed by boiling in three changes of distilled water. These experiments showed that the results to be presented in this paper were not affected by the small quantities of glycerol introduced when organisms were shifted to a new medium after first being collected and washed on a filter.

Preparation of cultures. Medium containing $1 \mathrm{mg}$. proline $/ \mathrm{ml}$. was inoculated from an agar slope and the culture shaken overnight at $37^{\circ}$. In the morning the organisms were collected on a membrane filter and resuspended to an optical density of about $\mathbf{0 . 0 5}$ (Zeiss spectrophotometer; see later) in fresh medium. This culture was incubated at $37^{\circ}$ for at least 2.5 generations to ensure that exponential growth at the characteristic rate had been established. The organisms were then collected and washed on a filter and resuspended in the specified media.

Balanced growth at low proline concentrations. This condition was achieved as follows. A given volume of medium was inoculated with exponentially growing organisms to an optical density of about 0.05. After incubating the culture with aeration for $15 \mathrm{~min}$. (about 0.2 generation time) a portion was removed which decreased the number of bacteria to that contained in the original inoculum. The 
culture was then restored to its initial volume by the addition of fresh medium containing sufficient proline to replace that used by the organisms and lost on removal of medium. This process was repeated 5 times. In a typical case $2000 \mathrm{ml}$. medium 63 containing $10 \mu \mathrm{g}$. proline $/ \mathrm{ml}$. was inoculated and after $15 \mathrm{~min} .260 \mathrm{ml}$. of culture were removed and replaced by an equal volume of fresh medium containing $21 \mu \mathrm{g}$. proline $/ \mathrm{ml}$. In this way the optical density of the culture was kept between 0.05 and 0.062 and the proline concentration between 10 and $8 \cdot 6 \mu \mathrm{g} . / \mathrm{ml}$.

Measurement of amino acid 'pools'. A carefully measured volume (500 ml.) of a culture of known optical density (between 0.05 and 0.07 ) was filtered rapidly ( $<2$ min.) through a $9 \mathrm{~cm}$. membrane filter and washed with six lots of $20 \mathrm{ml}$. each of medium 63 at $2^{\circ}$. The membrane was then carefully removed from the filter assembly, washed on the underside with cold medium from a wash bottle to remove any contaminant that might have splashed up from beneath when the vacuum was broken in the flask, and submerged in $6.0 \mathrm{ml}$. of $5 \%(\mathrm{w} / \mathrm{v})$ trichloroacetic acid (TCA) aqueous solution at $2^{\circ}$ in a Petri dish. After 15 min. the TCA solution was decanted and replaced by $4 \mathrm{ml}$. fresh cold TCA solution. After a further $15 \mathrm{~min}$. the second batch of TCA solution was decanted off, the membrane removed and the contents of the Petri dish washed out with 2 portions of $1.5 \mathrm{ml} .5 \%(\mathrm{w} / \mathrm{v})$ TCA solution. All extracts and washings were combined. This procedure liberated the 'pool' components of the cells but also dislodged some of the bacteria from the membrane. The 'pool' compounds were separated from the bacteria by filtering through a $2.9 \mathrm{~cm}$. membrane filter and washing the filter twice with $1.0 \mathrm{ml}$. of $5 \%$ (w/v) TCA solution. The total volume of filtrate obtained in this way was between 14.0 and $14.5 \mathrm{ml}$. To show that all the proline contained in such preparations had in fact been extracted from the cells the following control experiment was carried out. A filter, through which $500 \mathrm{ml}$. of culture grown in medium 63 containing $10 \mu \mathrm{g}$. proline $/ \mathrm{ml}$. had passed, was washed with $50 \mathrm{ml}$. of medium 63 containing $2 \mathrm{mg}$. proline (i.e. $400 \mu \mathrm{g}$. $/ \mathrm{ml}$.) and then with six $20 \mathrm{ml}$. portions of medium 63 . The pool concentration determined in this experiment was about 1.5 times the concentration characteristic of organisms grown in $10 \mu \mathrm{g}$. proline $/ \mathrm{ml}$. It is therefore unlikely that pool concentrations measured on cultures grown in media with $2 \mathrm{mg}$. or less proline/ml. were due to non-specific adsorption on the organisms or on the filters.

Proline was determined directly on $5 \mathrm{ml}$. samples of the extract by the method of Troll \& Lindsley (1955). When both proline and glutamic acid were to be determined, the extract itself was first treated with ether three times to remove the majority of the TCA and then desalted on $4.5 \mathrm{ml}$. columns of Dowex 1 (40-60 mesh; $\times 8 ; \mathrm{H}^{+}$form). The eluates were bubbled with air at $37^{\circ}$ for $20 \mathrm{~min}$. to remove ammonia and then taken to dryness at $100^{\circ}$ in a stream of air. Glutamic acid and proline were separated by two dimensional chromatography and estimated on the paper after spraying the appropriate areas with ninhydrin (Mandelstam, 1958) and with isatin, respectively (Acher, Fromageot \& Jutisz, 1950). The proline figures obtained in this way were checked by direct estimation of proline on representative samples removed before and after the desalting procedure.

Preparation of protein + cell wall hydrolysates. Samples containing about $1 \mathrm{mg}$. dry wt. of organism were fractionated to yield the protein +cell-wall fraction as 
described by Richmond (1960). This material was hydrolysed in $6 \mathrm{~N}-\mathrm{HCl}$ for $16 \mathrm{hr}$. at $105^{\circ}$ in sealed tubes. The $\mathrm{HCl}$ was evaporated at $100^{\circ}$ in a stream of air, remaining traces of acid being removed by successive additions of water and evaporation to dryness.

Chromatography and radioautography. The following solvents were used for the separation of amino acids: phenol + water + ammonia sp.gr. $0 \cdot 880(80+20+0 \cdot 3$, by vol.); $n$-butanol + acetic acid + water $(63+10+27$, by vol.); and methylethylketone + tert-butanol + water + diethylamine $(40+40+20+4$, by vol.; Redfield, 1953).

Protein + cell-wall hydrolysates were separated two-dimensionally in butanol + acetic acid + water followed by phenol + ammonia. Proline and glutamic acid in the pool experiments were separated in methylethylketone + tert.-butanol + water + diethylamine followed by butanol + acetic acid + water. The material was applied at the origin in $25 \mu \mathrm{l}$. distilled water, containing 50-100 $\mu \mathrm{g}$. of each amino acid. Whatman No. 3 paper was used throughout.

Radioautographs were prepared as described by Roberts et al. (1957). The material applied at the origin was monitored and the X-ray film developed after $10^{6}$ disintegrations/spot had occurred.

Fractionation of culture media. The organisms were separated from the media by filtration through a $2.7 \mathrm{~cm}$. membrane filter, and the filtrate collected in $1 / 10 \mathrm{th}$ volume of $20 \%(\mathrm{w} / \mathrm{v})$ TCA solution. The proline content of the media was determined by the method of Troll \& Lindsley (1955), and their radioactivity was estimated by plating $25 \mu \mathrm{l}$. samples directly on to $1 \mathrm{~cm} .{ }^{2}$ planchets and counting as described below. The ${ }^{14} \mathrm{C}$-glutamic acid in the growth medium was estimated after separation of the amino acid from other radioactive components by ionophoresis. When ${ }^{12} \mathrm{C}$-glutamate was present in the culture, 50 or $100 \mu \mathrm{l}$. portions of medium were streaked in the centre of a strip of ionophoresis paper with appropriate markers and the separation carried out for $3 \mathrm{hr}$. at $14 \mathrm{~V} / \mathrm{cm}$. in pyridine + acetic acid + water buffer (pH 6.0; Ryle, Sanger, Smith \& Kitai, 1955). After thoroughly drying the paper, the ${ }^{14} \mathrm{C}$-glutamate was located by spraying the marker regions with ninhydrin and then eluted into $3.0 \mathrm{ml}$. distilled water. The eluate was taken to dryness to remove traces of pyridine and redissolved in water. The specific activity of the ${ }^{14} \mathrm{C}$-glutamic acid was determined from radioactivity measurements and glutamate estimations with ninhydrin. When ${ }^{12} \mathrm{C}$-glutamate was not present in the medium during growth, $500 \mu \mathrm{g} .{ }^{12} \mathrm{C}$-glutamate $/ \mathrm{ml}$. was added to the filtrates as carrier.

Estimation of ${ }^{14} \mathrm{CO}_{2}$. A $10 \mathrm{ml}$. culture was grown in a closed system and bubbled with air at a rate of about $100 \mathrm{ml}$./min. The effluent gas was passed for a fixed time (usually $5 \mathrm{~min}$.) through $50 \mathrm{ml}$. $\mathrm{N}-\mathrm{NaOH}$ containing $0 \cdot 2 \mathrm{ml} \cdot 0 \cdot 25 \mathrm{M}-\mathrm{KHCO}_{3}$ as carrier. The total carbonate present in the $\mathrm{NaOH}$ was precipitated with excess $\mathrm{Ba}(\mathrm{OH})_{2}$, collected on a filter paper disk and the radioactivity determined at infinite thickness. The quantity of carrier used ensured that the radioactive carbon dioxide never constituted more than $5 \%$ of the total amount of carbonate precipitated.

Measurements of bacterial growth. Growth rates were measured turbidimetrically in a Zeiss Spectrophotometer (Model PMQ II) at $450 \mathrm{~m} \mu$ with a $1.0 \mathrm{~cm}$. light path. Under these conditions, for a culture growing in medium $63+$ proline, an optical density of $0 \cdot 100$ corresponds to a dry weight of organism of about $18 \mu \mathrm{g} . / \mathrm{ml}$, , and a viable count of about $7 \times 10^{7}$ bacteria/ml. (see Schaechter et al. 1958). 
Radioactivity determinations. Membrane filters were glued directly to $5 \cdot 7 \mathrm{~cm} .^{2}$ planchets for counting; other samples were plated on $1 \mathrm{~cm} .{ }^{2}$ planchets and dried at $65^{\circ}$. Counting was carried out with a Geiger-Müller tube and scaler or with a gas-flow counter (Friescke \& Hoepfner GMBH, Erlangen-Bruck, Germany). A minimum of $10^{3}$ counts above background were collected; background never exceeded $25 \%$ of the total count.

\section{RESULTS}

Growth of Salmonella typhimurium in proline and glutamic acid media

Preliminary experiments showed that Salmonella typhimurium would grow in medium 63 containing proline or L-glutamic acid as sole carbon source at rates of 0.70 and 0.90 doublings/hr., respectively. With proline +L-glutamic acid in the medium $1 \cdot 1$ doublings/hr. were obtained. Organisms growing in proline at the final rate for that amino acid upon addition of L-glutamic acid increased their growth

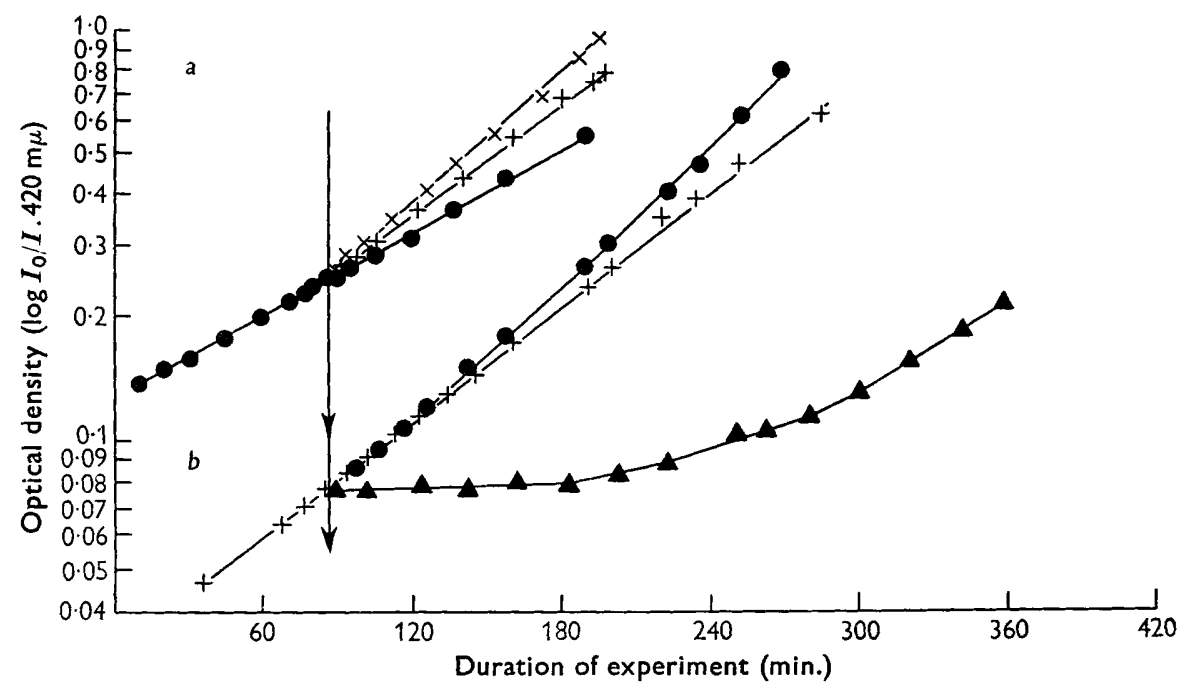

Fig. 1. Growth of Salmonella typhimurium in medium 63 containing different carbon sources. (a) A culture growing in medium $63+500 \mu \mathrm{g}$. proline $/ \mathrm{ml}$. (๑) was filtered at the point indicated by the arrow, washed on the filter with medium 63 and the organisms resuspended in medium 63 containing the following additions: $500 \mu \mathrm{g}$. proline $/ \mathrm{ml}$. (๑), $500 \mu \mathrm{g}$. glutamate $/ \mathrm{ml}$. $(+), 500 \mu \mathrm{g}$. proline $/ \mathrm{ml} .+500 \mu \mathrm{g}$. Na glutamate $/ \mathrm{ml}$. $(x)$. (b) A culture growing in medium $63+500 \mu \mathrm{g}$. Na glutamate $/ \mathrm{ml} .(+)$ was filtered at the point indicated by the arrow, washed on the filter with medium 63 and the organisms resuspended in medium 63 with the following additions: $500 \mu \mathrm{g}$. proline $/ \mathrm{ml}$. (A), $500 \mu \mathrm{g}$. $\mathrm{Na}$ glutamate $/ \mathrm{ml}$. (+), and $500 \mu \mathrm{g}$. proline $/ \mathrm{ml}$. $+500 \mu \mathrm{g}$. Na glutamate $/ \mathrm{ml}$. (๑).

rate to the high value characteristic of a glutamic acid + proline mixture. When organisms growing in proline medium were collected by filtration, washed and resuspended in glutamic acid medium, growth was resumed at the rate characteristic of glutamate alone. In both cases the new and higher growth rate was established within about one minute after glutamic acid was introduced (see upper set of curves in Fig. 1). On the other hand, organisms growing in medium containing L-glutamate alone increased their growth rate slowly when proline was added, and replacement of L-glutamate by proline led to a pronounced diauxie. As illustrated by lower set 
of curves of Fig. 1, it took several hours before the rate of growth characteristic of proline was established in a medium containing this amino acid as the sole carbon source. Clearly, our strain of $S$. typhimurium can switch readily from growth on proline to growth on glutamate, but not vice versa.

Effect of external concentration of proline or glutamic acid on the growth rate

In several cases the growth rate of bacteria has been shown to be independent of the external concentration of nutrilites over a wide range (e.g. Monod, 1942; Novick, 1955; Novick \& Szilard, 1950). This important observation was confirmed

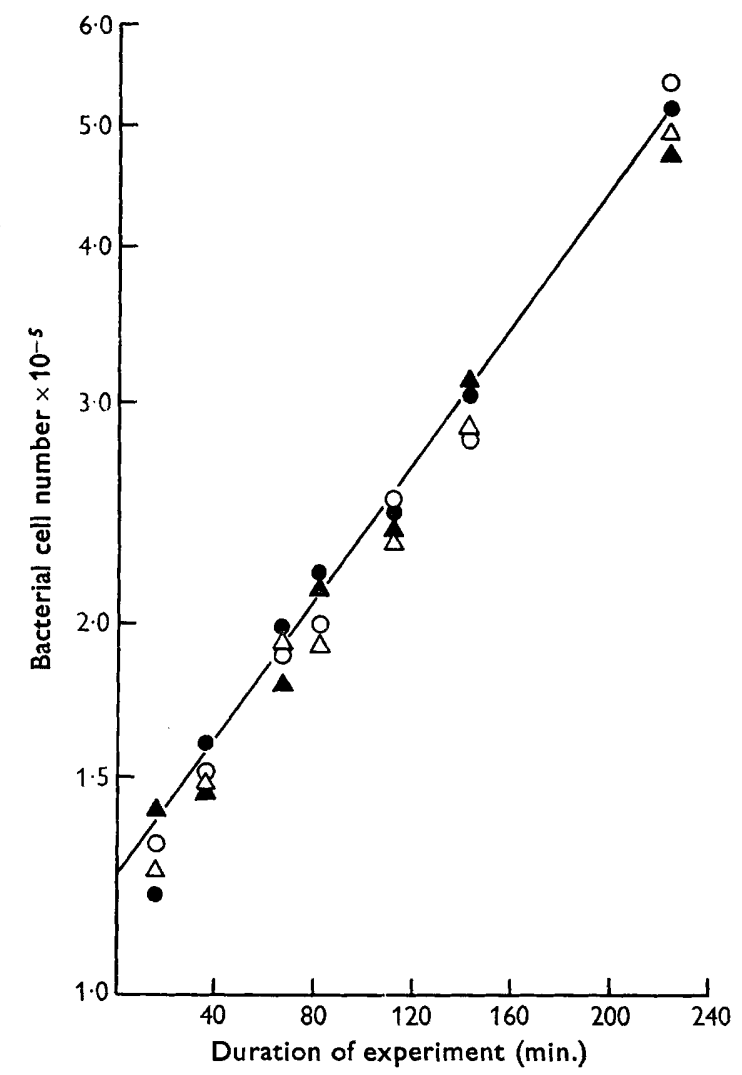

Fig. 2. Growth of Salmonella typhimurium in medium $63+$ different concentrations of proline. Inoculum: about $1.2 \times 10^{5} \mathrm{bacteria} / \mathrm{ml}$. Proline concentrations $/ \mathrm{ml}$. : $1.0 \mu \mathrm{g}$. (O), $10.0 \mu \mathrm{g}$. (O), $100 \mu \mathrm{g}$. (A), $1000 \mu \mathrm{g} .(\triangle)$. Samples measured by viable count.

in our experiments by measuring the growth rate of Salmonella typhimurium in media containing proline in concentrations from 1 to $1000 \mu \mathrm{g} . / \mathrm{ml}$. Organisms growing exponentially in medium with $100 \mu \mathrm{g}$. proline $/ \mathrm{ml}$. were inoculated to a concentration of $10^{5} \mathrm{organisms} / \mathrm{ml}$. into media containing $1,10,100$, and $1000 \mu \mathrm{g}$. proline/ml., respectively. By viable counts it was shown that the growth rate of all four cultures was the same over a period of at least two generations (Fig. 2). The same result was obtained when growth was followed turbidimetrically, with inocula of $3 \times 10^{7}$ organisms $/ \mathrm{ml}$. in the presence of $20,60,200,600$ and $2000 \mu \mathrm{g}$. proline $/ \mathrm{ml}$. 
Similar results were obtained with L-glutamic acid as sole carbon source. Thus within wide limits of concentration, the rate of balanced growth of these organisms was defined by the qualitative composition of the medium.

\section{Investigation of the rate-limiting reaction}

Flow of proline to the free amino acid ' pool'. The rate of growth in proline medium might be limited by the rate of flow of proline into the bacterial cells. Experiments were therefore carried out to decide whether the rate of inflow of proline could be

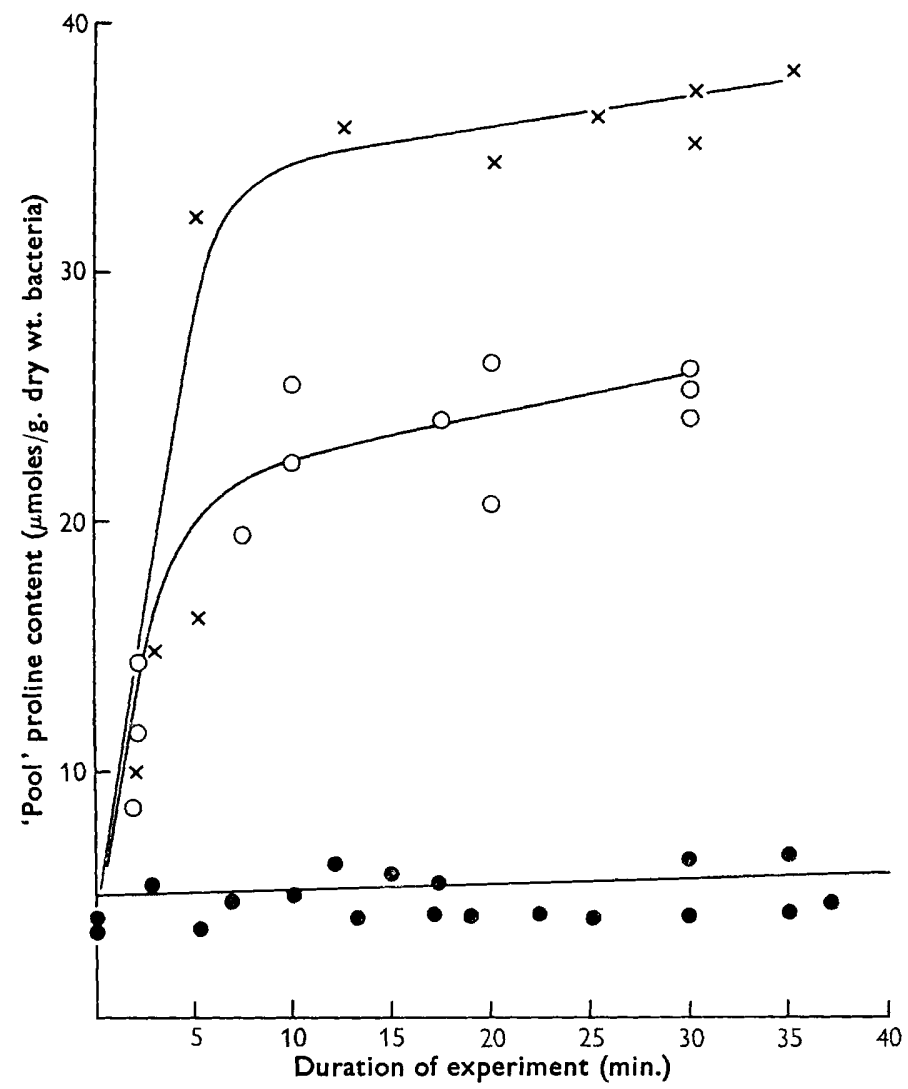

Fig. 3. Effect of changing the external proline concentration on the proline content of the free amino acid pool of Salmonella typhimurium.

Organisms were prepared for the experiment by the 'cycling procedure' (see Methods) in medium $63+10 \mu \mathrm{g}$. proline $/ \mathrm{ml}$. The organisms were then separated by filtration and resuspended (at time zero) to an optical density of about 0.05 in medium 63 containing the following concentrations of proline $(\mu \mathrm{g} . / \mathrm{ml}):. 10(0), 500(0), 1000(\times)$. Samples taken at intervals were treated to liberate the free amino-acid pool. The proline content of the pool was measured by the method of Troll \& Lindsley (1955).

increased above that required for growth at the characteristic rate. Organisms were grown under approximately steady state conditions in medium containing $10 \mu \mathrm{g}$. proline $/ \mathrm{ml}$. After 5 cycles of dilution (see Methods), half the culture was poured on to sufficient solid proline to raise the external concentration to $1 \mathrm{mg} . / \mathrm{ml}$. The other half of the culture was maintained in medium containing $10 \mu \mathrm{g}$. proline/ 
ml. Samples were taken in rapid succession from both cultures and the pool concentration of proline estimated chemically. After all the samples had been removed, incubation was continued for at least one generation, to ascertain that the growth rate was the same at both proline concentrations. Figure 3 shows the results from a number of experiments of this kind. In all cases, transfer of the organisms to a higher external proline concentration resulted in a rapid increase in the proline pool with no change in the growth rate. The increase was seven- to eight-fold after a shift from 10 to $1000 \mu \mathrm{g}$. $/ \mathrm{ml}$., and about five-fold after a shift from 10 to $500 \mu \mathrm{g} . / \mathrm{ml}$.

These results indicate that, during the short period when the proline pool increased from 15-20 to about $140 \mu \mathrm{mole} / \mathrm{g}$. the rate of flow of proline into the pool was about $20 \%$ higher than it was during balanced growth. Thus, if we disregard the unlikely possibility that growth was slowed down correspondingly during the build-up of the proline pool, we may conclude that the flow of proline from the medium to the free amino acid pool of the organisms did not restrict the growth rate. Results published by Britten (Britten \& McClure, 1961) indicate that a similar deduction can be made for Escherichia coli.

Dissimilation of carbon from proline. The degradative pathway for proline is not fully known, and glutamic acid is the only clearly identified product (Stetten, 1955; Vogel, 1955). It has been reported that radioactive proline can be converted to ornithine, citrulline and arginine by Neurospora crassa, Torolopsis utilis (Srb, Fincham \& Bonner, 1950; Fincham, 1953) and Escherichia coli (Vogel, Abelson \& Bolton, 1953) without the carbon passing through glutamic acid. Our experiments with Salmonella typhimurium show that most of the proline-carbon reached the protein of the organisms via glutamic acid. This was studied by measuring the effect of exogenous non-radioactive glutamic acid on the flow of radioactive carbon from ${ }^{14} \mathrm{C}$-proline to individual amino acids of the cell proteins. The reasoning is as follows. If all the proline-carbon flows through glutamate, the addition of ${ }^{12} \mathrm{C}$ glutamate should depress to an equal extent the flow of radioactivity to all amino acids in the protein. On the other hand, if certain amino acids were synthesized from proline without involving glutamic acid, these amino acids should be less affected by the addition of non-radioactive glutamate. Thus, if ornithine were synthesized directly from proline, the arginine isolated from the protein should have the same high specific activity as the administered proline. Figure 4 shows the effect of adding $1 \mathrm{mg}$. ${ }^{12} \mathrm{C}$-glutamate $/ \mathrm{ml}$. to a culture growing exponentially in medium containing $250 \mu \mathrm{g} .{ }^{14} \mathrm{C}$-proline $/ \mathrm{ml}$. $(0.03 \mu \mathrm{C} / \mu$ mole $)$. A second part of the culture, to which no glutamate was added, served as a control. Upon addition of ${ }^{12} \mathrm{C}$-L-glutamate the differential rate of incorporation of radioactive carbon into TCA-precipitable material was immediately decreased to about $35 \%$ of the control value. This diminished rate remained constant for at least three generations.

Samples from both cultures were treated to yield the protein + cell-wall fraction and this was hydrolysed to liberate the free amino acids. Table 1 shows that the flow of radioactivity to various amino acids in the protein, except to proline, was decreased approximately to the same extent by the addition of non-radioactive glutamate. Table 2 shows that the specific activities of certain amino acids including arginine and lysine, are nearly identical. Thus a direct, or preferential, conversion of proline to arginine is unlikely. From the errors involved in an experiment of this 
kind, we estimate that as much as $15 \%$ of the carbon from proline could flow by some route other than via glutamate without this being detected.

Given these results, it was of interest to see whether an increase in the external proline concentration led to an increase not only in the proline but also in the glutamic acid content of the free amino-acid pool. The experiment described in the previous section was therefore repeated, the pool material this time being desalted on a Dowex 1 column and the proline and glutamic acid determined chromatographically. As before, an increase in the external concentration of proline from

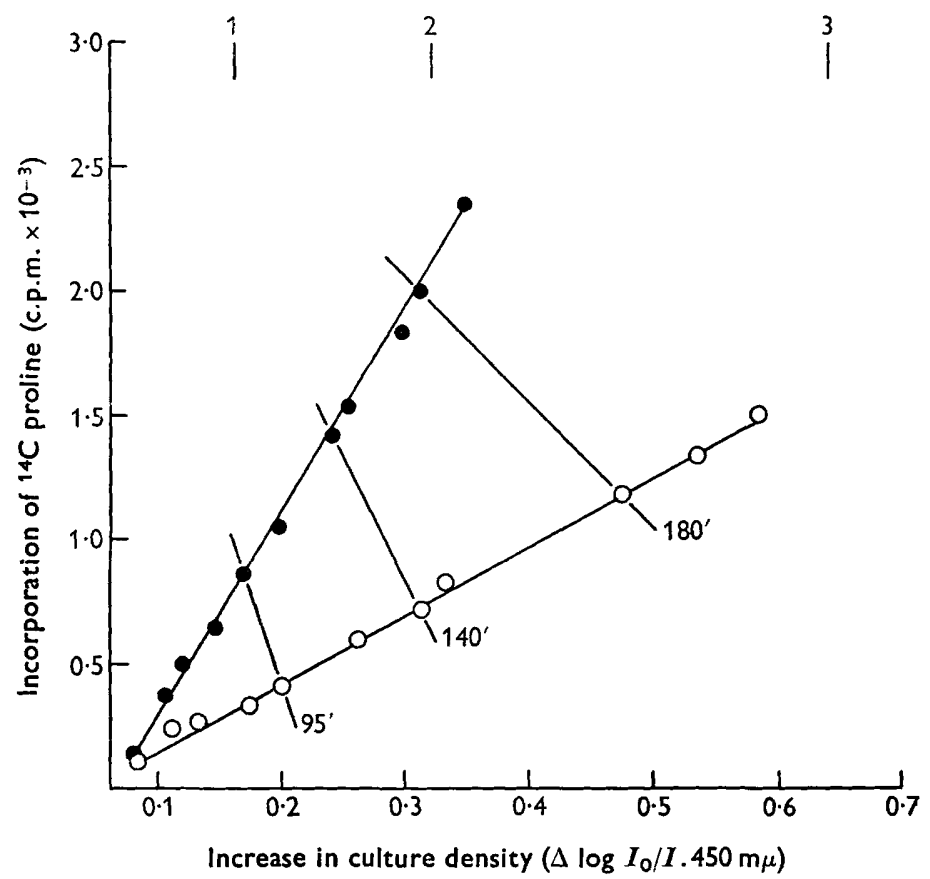

Fig. 4. The effect of addition of ${ }^{12} \mathrm{C}$-glutamate $(1 \mathrm{mg} . / \mathrm{ml}$.) on the incorporation of ${ }^{14} \mathrm{C}$-proline into Salmonella typhimurium.

$S$. typhimurium was grown in medium 63 containing $500 \mu \mathrm{g} .{ }^{14} \mathrm{C}$-proline $/ \mathrm{ml} .(0 \cdot 03 \mathrm{C} /$ mole) alone (O), or proline $+1 \mathrm{mg}$. glutamate $/ \mathrm{ml}$. (๑). Samples were taken at intervals into $5 \%(\mathrm{w} / \mathrm{v})$ TCA solution at $2^{\circ}$ and the radioactive content of the organisms determined by the membrane filter technique (see Methods). Samples for hydrolysis were removed 95,140 and 180 min., respectively, after addition of ${ }^{14} \mathrm{C}$-proline. At the top of the frame the figures 1,2 and 3 indicate generations of growth (doublings) from time of addition of the radioactivity.

$10 \mu \mathrm{g}$. to $1000 \mu \mathrm{g} . / \mathrm{ml}$. caused an eight-fold increase in the proline content of the pool. In contrast, the glutamic acid pool only increased about 1-3-fold (see Fig. 5). This relative stability of the glutamate pool, together with the fact that changes in the external proline concentration had no effect on the growth rate, indicate that the rate at which proline was converted to glutamic acid was itself independent of the external proline concentration. We have seen that addition of glutamate to the proline medium immediately increased the growth rate, and thus the flux of carbon derived from glutamate. Experiments similar to those presented in Figs. 3 and 5 showed that in this case the glutamic acid pool increased about ten-fold. 
Before concluding that the rate of conversion of proline to glutamic acid is independent of the external proline concentration one must make sure that, at high proline concentrations, excess glutamic acid, or products thereof, are not excreted into the medium. This possibility was tested by inoculating exponentially growing organisms into a medium containing $265 \mu \mathrm{g} .{ }^{14} \mathrm{C}$-proline/ml., and allowing growth to continue until the proline was exhausted. In this way the metabolism of the organisms could be studied under conditions in which the external proline concentration decreased from $250 \mu \mathrm{g} . / \mathrm{ml}$. to nil. During this period the following factors were measured: (1) the incorporation of radioactivity into whole bacteria; (2) the incorporation of radioactivity into TCA-insoluble cell material; (3) the

Table 1. Effect of addition of ${ }^{12} \mathrm{C}$-glutamate on the flow of radioactivity from ${ }^{14} \mathrm{C}$-proline to the amino acids of bacterial protein in Salmonella typhimurium

\begin{abstract}
${ }^{12} \mathrm{C}$-glutamate $(1 \mathrm{mg} . / \mathrm{ml}$.) was added to half of a culture of $S$. typhimurium growing in medium 63 containing $250 \mu \mathrm{g}$. ${ }^{14} \mathrm{C}$-proline $(0.03 \mathrm{C} / \mathrm{mole})$. The other half was incubated without addition of glutamate. Samples taken as indicated below were treated to yield the protein + cell-wall fractions of the organisms which were hydrolysed to give free amino acids. These were separated by chromatography and their positions located by radioautography. The quantity of radioactivity in each spot was estimated after elution. The results are quoted in relation to a value for proline of $1 \cdot 0$ (see also Fig. 4).
\end{abstract}

\begin{tabular}{|c|c|c|c|c|c|c|c|c|c|}
\hline \multirow[b]{2}{*}{ Sample... } & \multicolumn{4}{|c|}{ Medium $63+{ }^{14} \mathrm{C}$-proline } & \multicolumn{4}{|c|}{ Medium $63+{ }^{14} \mathrm{C}$-proline $+{ }^{12} \mathrm{C}$-glutamate } & \multirow{3}{*}{$\begin{array}{c}\text { Average } \\
\% \text { of } \\
\text { control }\end{array}$} \\
\hline & 1 & $\mathbf{2}$ & $\mathbf{3}$ & Average & 1 & $\mathbf{2}$ & $\mathbf{3}$ & Average & \\
\hline Time of sample & 95 & 140 & 180 & & 95 & 140 & 180 & & \\
\hline $\begin{array}{l}\text { Optical } \\
\text { density } \ldots\end{array}$ & $0 \cdot 091$ & $0 \cdot 157$ & 0.228 & & $0 \cdot 108$ & $0 \cdot 221$ & 0.373 & & \\
\hline Leu/Ileu & $1 \cdot 3$ & $1 \cdot 2$ & $1 \cdot 1$ & $\mathbf{1 \cdot 2}$ & $0 \cdot 45$ & 0.37 & 0.35 & $\mathbf{0} \mathbf{3 9}$ & $\mathbf{3 5}$ \\
\hline Phe/Val. & $1 \cdot 4$ & $1 \cdot 4$ & $1 \cdot 2$ & $1 \cdot 3$ & $0 \cdot 45$ & 0.50 & 0.53 & 0.47 & 35 \\
\hline Tyr & $\mathbf{0} \cdot \mathbf{3 0}$ & 0.35 & $0 \cdot 30$ & 0.32 & - & $(0 \cdot 13)$ & $0 \cdot 18$ & $0 \cdot 15$ & - \\
\hline Ala & $1 \cdot 0$ & 0.95 & 0.87 & 0.94 & $\mathbf{0} \cdot \mathbf{3 0}$ & $0 \cdot 28$ & 0.35 & 0.27 & 35 \\
\hline Thr & $0 \cdot 25$ & $0 \cdot 3$ & 0.27 & $0 \cdot 27$ & $(0 \cdot 1)$ & $0 \cdot 12$ & 0.08 & 0.11 & (24) \\
\hline Ser/Gly & 0.95 & 0.9 & $1 \cdot 15$ & 0.95 & 0.32 & 0.36 & 0.35 & $\mathbf{0 . 3 4}$ & 28 \\
\hline Glu & $2 \cdot 1$ & 1.9 & 1.8 & 1.95 & 0.65 & 0.75 & 0.80 & $0 \cdot 70$ & 37 \\
\hline Lys/Arg & 1.7 & 1.8 & 1.8 & $1 \cdot 78$ & 0.60 & 0.70 & 0.77 & $0 \cdot 69$ & 39 \\
\hline Asp & $1 \cdot 2$ & $1 \cdot 4$ & 1.7 & $1 \cdot 42$ & $0 \cdot 40$ & $0 \cdot 37$ & 0.45 & 0.41 & 29 \\
\hline Pro & 1.0 & 1.0 & 1.0 & 1.0 & 1.0 & $1 \cdot 0$ & 1.0 & 1.0 & - \\
\hline
\end{tabular}

Bracketed values: radioactivity too low for accurate estimation. - , sample lost.

Table 2. Specific radioactivity of certain amino acids isolated from the protein + cell-wall fractions of Salmonella typhimurium growing in ${ }^{14} \mathrm{C}$-proline $(250 \mu \mathrm{g} . / \mathrm{ml}$.: $0.03 \mathrm{C} /$ mole $) \pm{ }^{12} \mathrm{C}$-glutamate $(1 \mathrm{mg} . / \mathrm{ml}$. $)$

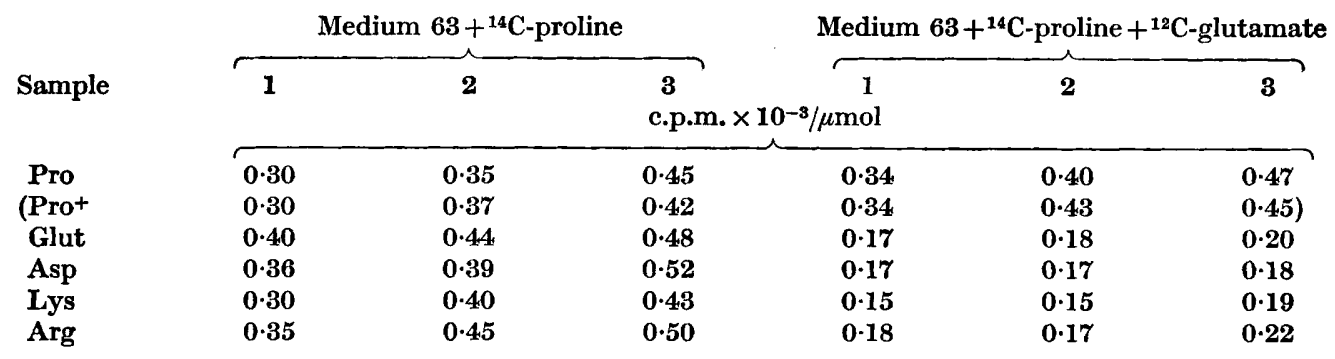

$\mathrm{Pro}^{+}=$Theoretical values for the specific activity of proline calculated from the initial specific activity of the ${ }^{14} \mathrm{C}$-proline added and the unlabelled inoculum added at the beginning of the experiment. (See also Table 1.) 
disappearance of proline from the growth medium; (4) the radioactivity remaining in the medium after treatment with acid to liberate ${ }^{14} \mathrm{CO}_{2} ;(5)$ the appearance of ${ }^{14} \mathrm{C}$-glutamate in the medium. Figure 6 shows the results of these measurements. In all cases the differential plots are approximately linear, indicating that the parameters measured were independent of the external proline concentration. No ${ }^{14} \mathrm{C}$-glutamate was detected in the growth medium.

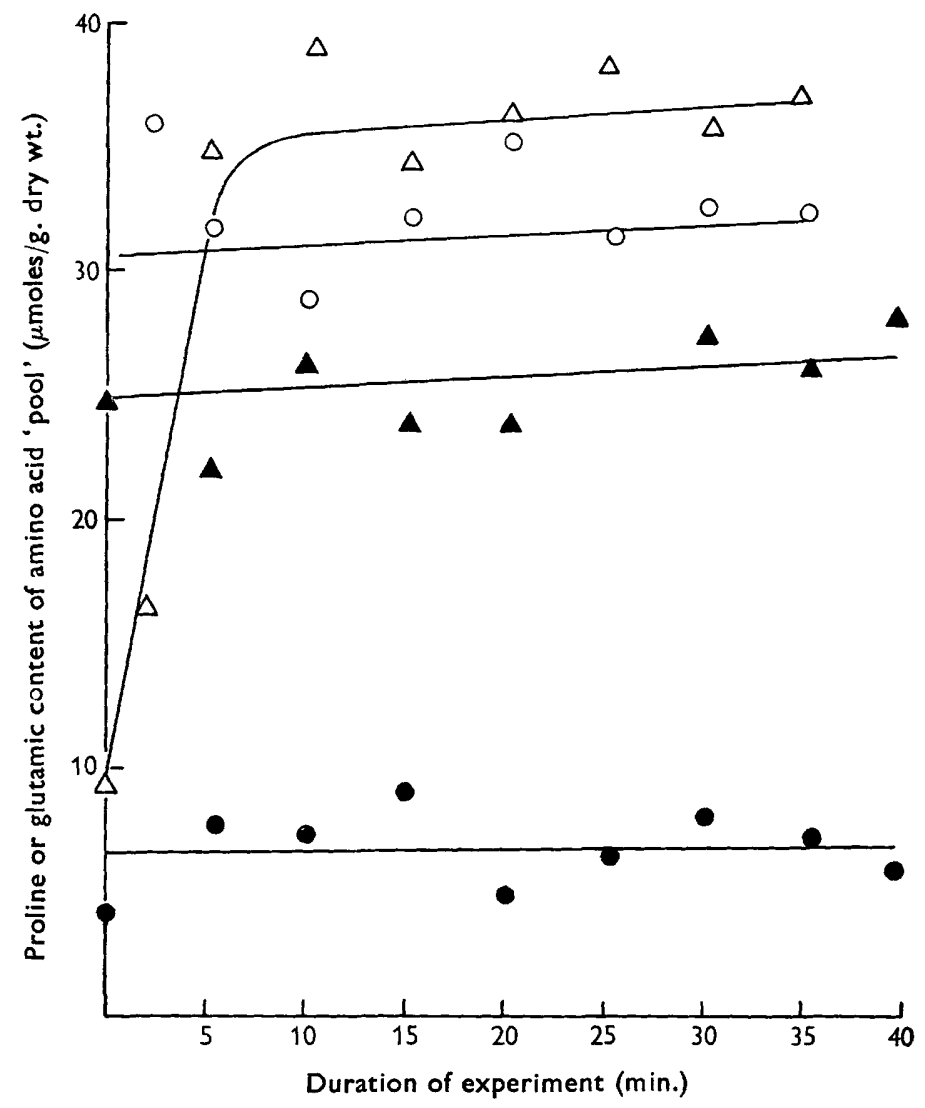

Fig. 5. Effect of changing the external proline concentration on the proline and glutamic acid content of the free amino acid pool in Salmonella typhimurium.

The organisms were prepared for the experiment by the 'cycling procedure' (see Methods) in medium $63+10 \mu \mathrm{g}$. proline $/ \mathrm{ml}$., separated by filtration and resuspended to an optical density of about 0.05 in media containing $10 \mu \mathrm{g} . / \mathrm{ml}$. ( $)$ and $\Delta$ ) and 1000 $\mu \mathrm{g} . / \mathrm{ml}$. $(O$ and $\triangle)$ of proline. The proline $(\triangle)$ and $(\bullet)$, and the glutamic acid $(\Delta)$ and (O) content of the pool was measured after desalting and separation by chromatography.

From the data presented in Fig. 6 estimates of the non-proline radioactivity remaining in the medium at various times were obtained by subtracting from (4) the activity corresponding to the proline still present in the medium. As shown by the two descending lines in Fig. 6 this non-proline activity built up in the medium at a constant differential rate, and at the end of the experiment it amounted to about $20 \%$ of the input activity. The ${ }^{14} \mathrm{CO}_{2}$ produced under these conditions was determined in a special experiment, since the errors involved in calculating the $\mathrm{CO}_{2}$ production from the data of Fig. 6 are very large. Figure 7 shows that the differential 
rate of $\mathrm{CO}_{2}$ production remained constant until more than $90 \%$ of the proline had been consumed. At this point about $12 \%$ of the input activity had been released as ${ }^{14} \mathrm{CO}_{2}$. Thus, of the generally labelled proline consumed in these experiments about $\frac{2}{3}$ of the carbon were incorporated into cell material and $\frac{1}{3}$ was released into the medium.

In summary, large changes in the external proline concentration have correspondingly large effects on the proline pool in the cells, but no effect on the growth rate of the organisms, and little, if any, effect on the size of the glutamic acid pool or on the pattern of assimilation of carbon from proline. We interpret this to mean

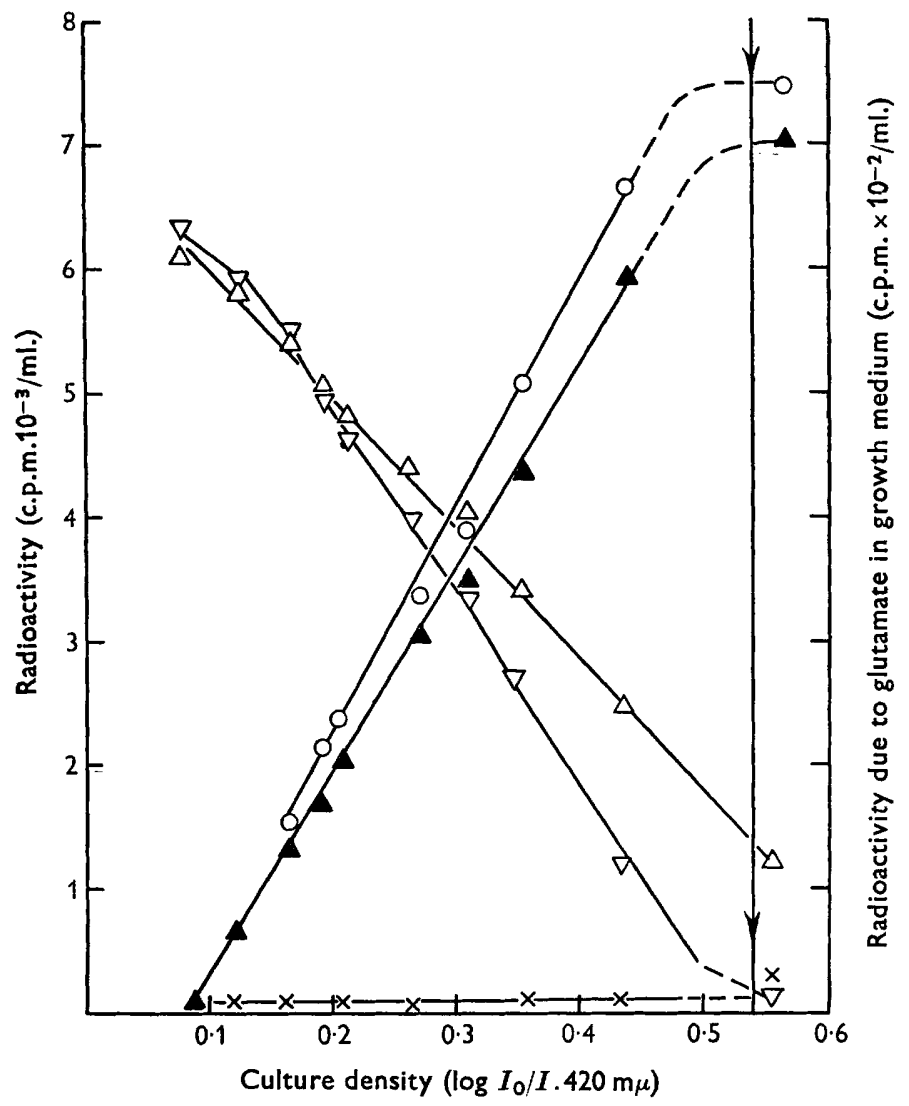

Fig. 6. Analysis of various culture components during the utilization and exhaustion of proline.

Salmonella typhimurium was grown in medium 63 containing $265 \mu \mathrm{g} .{ }^{14} \mathrm{C}$-proline $/ \mathrm{ml}$. $(0.03 \mathrm{C} / \mathrm{mole})$ until the proline was exhausted. Samples of the culture $(2.5 \mathrm{ml}$.) were filtered into $1 / 10$ th vol. $20 \%(w / v)$ TCA solution and the concentration of proline and the radioactivity present in the medium estimated directly on 0.5 and $0.05 \mathrm{ml}$. samples, respectively. The quantity of glutamic acid was estimated on a further $1.0 \mathrm{ml}$. of the filtrate as described under Methods. The radioactivity in the medium $(\triangle)$ and the radioactivity due to glutamie acid in the medium $(x)$ are plotted directly. The external proline concentration is plotted $(\nabla)$ after conversion to c.p.m./ml. from the initial specific radioactivity of the proline added to the medium. Further $1.0 \mathrm{ml}$. samples were filtered to measure the total radioactivity incorporated into the organisms (O) and the radioactivity incorporated into the TCA precipitable portion of the bacteria $(\Delta)$. The theoretical point of exhaustion of proline is shown by the arrow. Initial suspension optical density $0 \cdot 08$. 
that the rate at which proline is converted to glutamic acid is largely responsible for the fact that Salmonella typhimurium grows slower with proline than with glutamic acid as the sole carbon source.

This conclusion is based on the following reasoning. At different external proline concentrations a series of steady states of growth are observed which are identical with respect to growth rate, pattern of dissimilation of proline and intracellular concentration of glutamic acid, and which differ only with respect to the intracellular concentration of proline. In these cases the rate of flow of carbon from

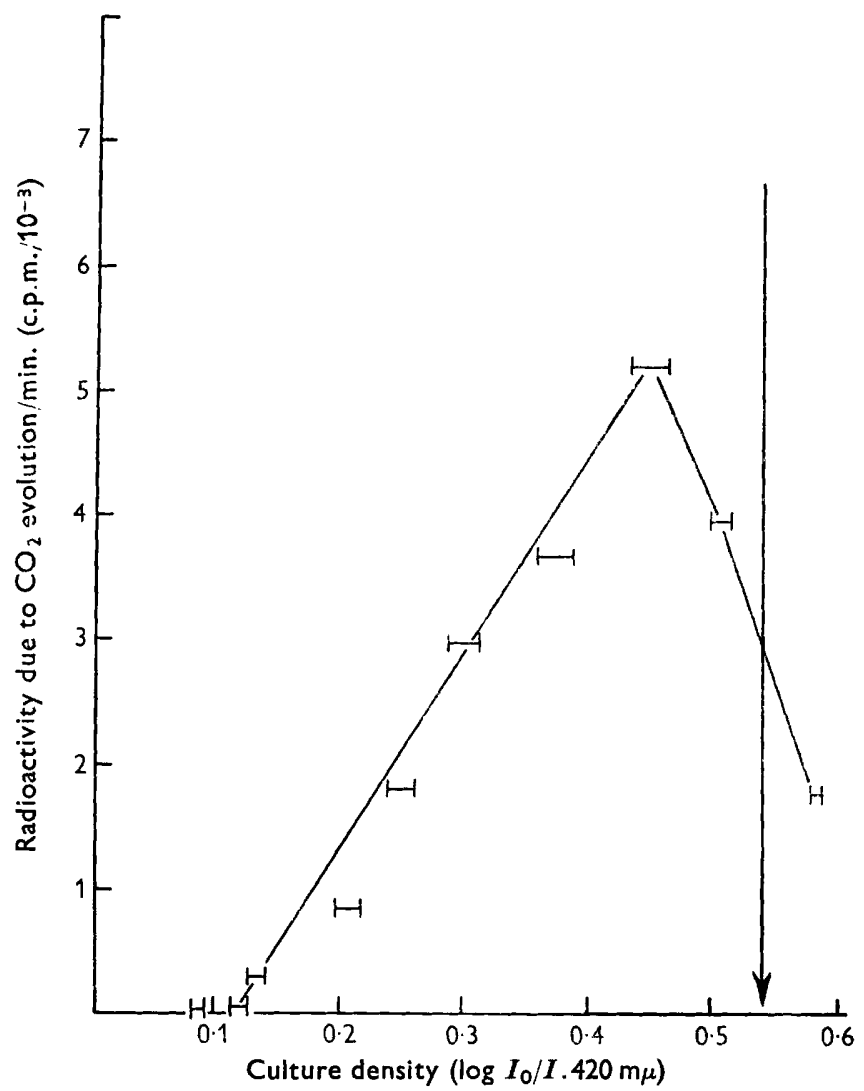

Fig. 7. Liberation of ${ }^{14} \mathrm{CO}_{2}$ during utilization and exhaustion of proline. Salmonella typhimurium was grown in medium $63+{ }^{14} \mathrm{C}$-proline $(250 \mu \mathrm{g} . / \mathrm{ml}).(0.03$ $\mathrm{C} / \mathrm{mole}$ ) until the proline was exhausted. The culture (initial optical density, $\mathbf{0} \cdot 115$ ) was kept in a closed system and the total amount of ${ }^{14} \mathrm{CO}_{2}$ liberated in 5 min. periods estimated. The theoretical point of exhaustion of proline is shown by the arrow. The bars across each point represent the increase in culture optical density during the $5 \mathrm{~min}$. period in which the sample was collected.

proline into general cell mass must therefore be the same, and the enzymes responsible for converting proline to glutamic acid must be saturated; i.e. the growth rate must be limited by the capacity of this enzyme system.

It is perhaps surprising that a constant glutamate pool of about $30 \mu$ mole $/ \mathrm{g}$. should be maintained under these conditions. We feel that the constancy of this pool reflects the fact that the enzymes responsible for converting proline to gluta- 
mate seem to be saturated even at low external proline concentrations. In the steady state of growth the intracellular concentration of glutamic acid obviously must assume the value required to maintain the constant flow of glutamate. The observed glutamate concentration (pool size) may therefore be looked upon as a general characteristic of the enzyme system which makes glutamate-carbon available for growth. This interpretation seems reasonable since the addition of glutamate to the medium has the two-fold effect of increasing the growth rate and the size of the glutamate pool. If we assume that this increase in pool size is necessary to bring about an increase in growth rate, it follows that the enzymes responsible for converting glutamate to cell mass are not saturated during growth with proline as sole carbon source.

\section{Effect of the synthesis of the proline-degrading enzymes on growth rate}

As mentioned above, the proline-degrading enzymes might constitute so large a fraction of the cell protein that the relative size of other enzyme systems, and thereby the growth rate, was decreased. A restriction of this kind might operate in addition to the limitations discussed above. If the synthesis of the prolinedegrading enzymes is to account wholly, or in part, for the fact that the growth rate on proline is less than that on glutamate, the synthesis of these enzymes should cease or be markedly decreased on addition of glutamate to a proline culture. Unfortunately, no reliable method is available which directly measures the quantity of proline-degrading enzymes present in these organisms. An indirect estimate can, however, be obtained by measuring the effect of addition of ${ }^{12} \mathrm{C}$-glutamate on the incorporation and dissimilation of ${ }^{14} \mathrm{C}$-proline. As we have seen (p. 276 and Fig. 4), addition of glutamate to a culture growing with ${ }^{14} \mathrm{C}$-proline led to an immediate increase in the growth rate and to an immediate decrease in the differential rate of incorporation of radioactivity into TCA-insoluble cell material. Since this decreased rate of uptake remained constant over more than three generations, the addition of glutamate did not completely inhibit the function of or repress the production of the proline-degrading enzymes.

A more detailed study of the effect of added glutamic acid on the amount of radioactivity passing through the proline-degrading enzymes was made as follows. A culture was grown in medium containing $100 \mu \mathrm{g}$. ${ }^{14} \mathrm{C}$-proline $(0 \cdot 03 \mathrm{C} / \mathrm{mole})$ and the dissimilation of radioactivity followed in the presence and the absence of $1 \mathrm{mg} . /$ ml. of ${ }^{12} \mathrm{C}$-glutamate. As in the experiment of Fig. 6, the following parameters were measured: (1) and (2) the incorporation of radioactivity into whole organisms and into TCA-insoluble cell material, respectively; (3) the disappearance of proline from the medium; (4) the disappearance of radioactivity from the medium; (5) the appearance of ${ }^{14} \mathrm{C}$-glutamate in the medium. These measurements permitted a calculation of the differential rate of appearance of radioactivity due to compounds other than proline. In the presence of glutamate the rate of incorporation of ${ }^{14} \mathrm{C}$ proline was about $30 \%$ of that achieved in the control culture. Similarly, glutamate depressed the quantities of radioactivity appearing as compounds other than proline. Under these conditions, however, the glutamate in the growth medium became radioactive and the flow of radioactivity by this route amounted to about $12 \%$ of the incorporation of radioactivity into TCA-insoluble cell material. Figure 8 summarizes the results of this experiment. 
Our experiments show that the addition of glutamate to cultures grown with proline alone resulted in an immediate partial inhibition of the function of the proline-degrading enzymes. Thus the rate of production of glutamic acid from radioactive proline, taking into account the activity appearing in the medium, was immediately decreased to a fixed value of about $\frac{1}{3}$ when ${ }^{12} \mathrm{C}$-glutamate was added. The constancy of this value shows that the synthesis of the proline-degrading

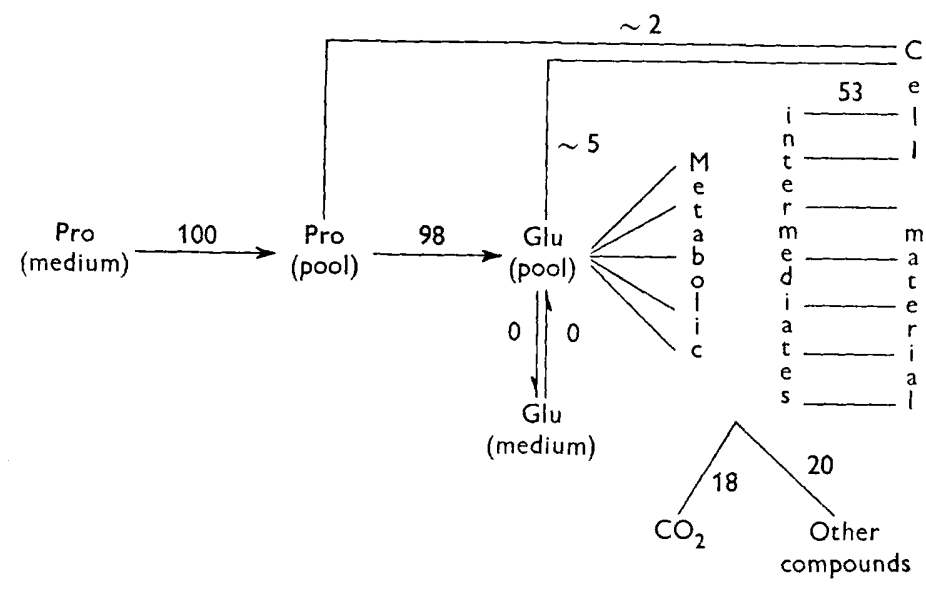

$a$

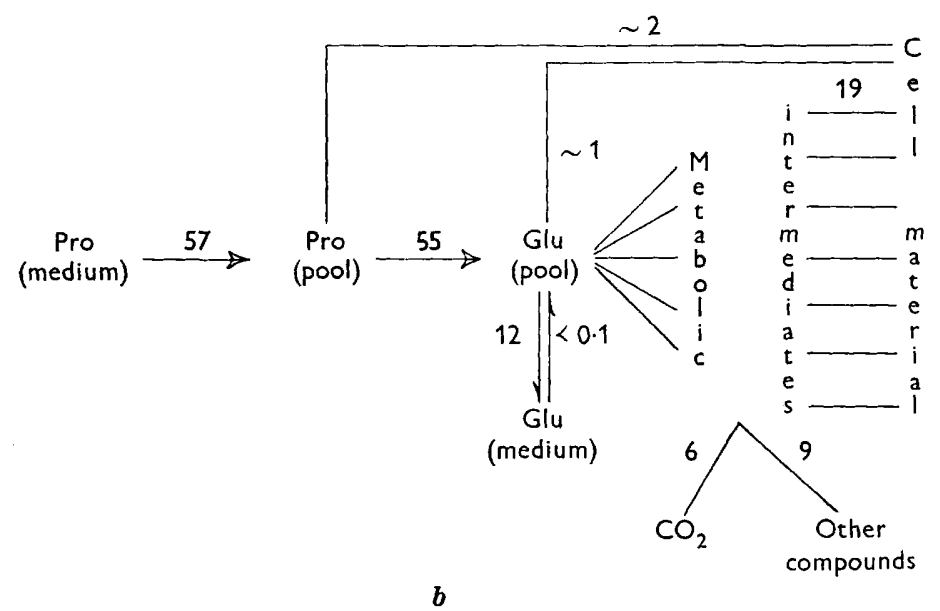

Fig. 8. Diagram to show the flow of carbon from ${ }^{14} \mathrm{C}$-proline through cultures of Salmonella typhimurium growing in medium $63+{ }^{14} \mathrm{C}$-proline (500 $\mu \mathrm{g}$. $/ \mathrm{ml}$.; $0 \cdot 03 \mu \mathrm{C} / \mu$ mole) (Fig. $8 a$ ) and medium $63+{ }^{14} \mathrm{C}$-proline $+{ }^{12} \mathrm{C}$-glutamate $(500 \mu \mathrm{g}$./ml. $)$. The differential rate of uptake of radioactivity by organisms growing in proline as sole carbon source is taken as 100. When organisms grow on mixtures of proline and glutamate, part of the carbon required for growth comes from the glutamate, and the differential rate of uptake of radioactivity for the proline in the medium is decreased.

enzymes was not completely repressed. Partial repression cannot be excluded, but the fact that the differential rates of disappearance and of dissimilation of ${ }^{14} \mathrm{C}$ proline remained constant for several generations after addition of glutamate argues against this possibility. 
Considering that the growth rate is immediately increased when glutamate is added to a proline culture, and since a case cannot be made for simultaneous repression of the synthesis of a sizable fraction of the enzyme protein of the cell, our conclusion is that the rate of conversion of proline to glutamic acid is the factor mainly responsible for the cells growing more slowly with proline than with glutamic acid as sole carbon source.

This work was supported by a Fellowship awarded to one of us (M.H.R.) and a grant-in-aid given to the University Institute of Microbiology by the CIBA Fellowship Trust.

\section{REFERENCES}

Acher, R., Fromageot, C. \& Jutrsz, M. (1950). Séparations chromatographiques d'acides aminés et de peptides. Avec une note sur le dosage de la proline. Biochim. biophys. Acta, 5, 81.

Britten, R. \& McClure, R. (1961). Amino acid pool in E. coli. Bact. Rev. (to be published).

Fincham, J. R. S. (1953). Ornithine transaminase in Neurospora and its relation to the biosynthesis of proline. Biochem. J. 53, 313.

MANDELSTAM, J. (1958). The free amino acids in growing and non-growing populations of Escherichia coli. Biochem. J. 69, 103.

Monon, J. (1942). Recherches sur la Croissance des Cultures Bactériennes. Paris, 1958 (2. ed.).

Novick, A. (1955). Growth of bacteria. Annu. Rev. Microbiol. 9, 97.

Novick, A. \& Szilard, L. (1950). Experiments with the chemostat on spontaneous mutations of bacteria. Proc. nat. Acad. Sci., Wash. 36, 708.

Novick, A. \& Weiner, M. (1957). Enzyme induction as an all-or-none phenomenon. Proc. nat. Acad. Sci., Wash. 43, 553.

Redfield, R. R. (1953). Two dimensional paper chromatographic systems with high resolving power for amino acids. Biochim. biophys. Acta, 10, $\mathbf{3 4 4}$.

Richmond, M. H. (1960). Incorporation of $p$-fluorophenylalanine into exopenicillinase by Bacillus cereus. Biochem. J. 77, 121.

Roberts, R. B., Abelson, P. H., Cowie, D. B., Bolton, E. T. \& Britten, R. J. (1957). Studies of biosynthesis in Escherichia coli. Carnegie Inst. Wash. Publ. no. 607, 2nd Printing.

Ryle, A. P., Sanger, F., Smith, L. F. \& Krtat, R. (1955). The disulphide bonds of insulin. Biochem. J. 60, 541.

Schaechter, M., MaAløe, O. \& KJeldgaArd, N. O. (1958). Dependency on medium and temperature of cell size and chemical composition during balanced growth of Salmonella typhimurium. J. gen. Microbiol. 19, 592.

Srb, A. M., Fincham, J. R. S. \& Bonner, D. (1950). Evidence from gene mutations in Neurospora for close metabolic relationships between ornithine, proline and $\alpha$-amino$\delta$-hydroxy-valeric acid. Amer. J. Bot. 37, 533.

Stetten, M. R. (1955). Amino Acid Metabolism, p. 277. Ed. W. D. McElroy \& B. Glass. Baltimore: Johns Hopkins Press.

Troll, W. \& Lindsley, J. (1955). A photometric method for the determination of proline. J. biol. Chem. 215, 655.

Vogel, H. J. (1955). Amino Acid Metabolism, p. 335. Ed. W. D. McElroy \& B. Glass. Baltimore: Johns Hopkins Press.

Vogel, H. J., Abelson, P. H. \& Bolton, E. T. (1953). On ornithine and proline synthesis in Escherichia coli. Biochim. biophys. Acta, 11, 584. 